\title{
KANTOR NIRKABEL SEBAGAI TEROBOSAN BUDAYA KERJA BARU BAGI PEKERJA INDIVIDUAL
}

\author{
Fauzia Latif \\ Jurusan Desain Interior, School of Design, BINUS University \\ Jln. K.H. Syahdan No.9, Palmerah, Jakarta Barat 11480 \\ fauzia.latif@gmail.com
}

\begin{abstract}
Today's technology much influences people's working environment. The current technology has created a working culture that is not rigid and conventional, but a flexible working environment, in terms of working site, how to work, and the products. A wireless office with its facilities is a breakthrough for both individual worker and teams in the modern era.
\end{abstract}

Keywords: technology, working culture, wireless office

\begin{abstract}
ABSTRAK
Teknologi masa kini sangat memengaruhi manusia dalam bekerja. Teknologi yang terbaru menciptakan suatu budaya kerja yang tidak lagi kaku dan konvensional, melainkan berubah menjadi lebih fleksibel, baik dalam tempat bekerja, cara bekerja, dan produk yang dihasilkan. Suatu kantor nirkabel dengan fasilitas di dalamnya merupakan suatu terobosan bagi pekerja individual atau sebuah tim, dalam bekerja di era modern.
\end{abstract}

Kata kunci: teknologi, budaya kerja, kantor nirkabel 


\section{PENDAHULUAN}

Teknologi adalah suatu karya manusia yang bertujuan untuk membuat kehidupan manusia lebih mudah dalam mencapai tingkat kebutuhan yang lebih tinggi. Kemajuan teknologi tersebut telah menjadi bagian dari kehidupan manusia sehari-hari. Dalam perjalanan sejarah, teknologi mulai dari revolusi industri, revolusi energi, dan revolusi informasi. Revolusi industri merubah kehidupan manusia dalam pola manufaktur dan sistem transportasi. Revolusi energi merubah kehidupan manusia dengan ditemukannya listrik dan elektromagnetis, sedangkan revolusi informasi merubah kehidupan manusia sejak munculnya fenomena cyberspace dan Internet yang memicu pertumbuhan bisnis berbasis teknologi informasi. Oleh karena itu, teknologi yang berkembang dalam peradaban manusia ini menjadi salah satu unsur kebudayaan dan peradaban universal. Kemajuan teknologi informasi ini mengakibatkan pekerjaan menjadi terkomputerisasi dan tidak mengenal batas-batas geografis lagi. Selain itu pekerjaan menjadi lebih efisien. Dengan berbentuk data komputer, maka para pekerja individual hanya membutuhkan sebuah laptop untuk bekerja. Perkembangan teknologi informasi saat ini bergerak ke arah teknologi nirkabel (wireless). Penggunaan gelombang sebagai pengantar data, mulai dikembangkan karena lebih fleksibel dan lebih mudah bagi pengguna (users friendly). Penggunaan teknologi wireless ini sudah mulai banyak digunakan, dari laptop, tabulet computer, handphone, hingga printer. Jenis wireless sendiri ada yang menggunakan infrared (gelombang infra merah), bluetooth, dan Wi-Fi (gelombang frekuensi tinggi).

Seiring dengan globalisasi dan kemajuan teknologi, juga terjadi persaingan yang ketat di dalam berbisnis. Hal ini menuntut mereka untuk memaksimalkan waktu dalam bekerja dan tidak ingin waktu mereka tersita oleh jarak. Maka terciptalah lifestyle baru di kalangan pekerja individual. Perubahan perilaku pekerja individual di era teknologi informasi ini cenderung lebih memiliki mobilitas yang tinggi dan tidak terikat oleh waktu. Contoh orang yang bekerja dengan gaya hidup seperti ini adalah freelance arsitek, graphic designer, author, sales marketing, event organizer. Lifestyle baru ini membuat pekerja individual informasi memerlukan suatu teknologi canggih (highend), selain untuk mempermudah urusan pekerjaan mereka, juga digunakan sebagai simbol status sosial/prestise mereka di mata klien. Oleh karena itu, pengguna jasa pekerja individual ini adalah dari kalangan menengah ke atas, sehingga menjaga citra dan kepercayaan adalah salah satu hal yang penting.

Para pekerja individual cenderung berlomba dengan waktu dan persaingan di dalam lapangan pekerjaannya. Hal tersebut mengakibatkan kurangnya waktu untuk beristirahat dan menenangkan pikiran, sehingga pekerjaan ini memiliki tingkat stres yang tinggi. Oleh karena itu perlu adanya suatu tempat yang dapat mewadahi para pekerja individual untuk tetap melakukan pekerjaannya namun dalam kondisi yang santai agar mereka tidak terlalu stres. Tempat tersebut tidak membosankan dan juga harus dapat mengefisienkan waktu yang dipergunakan. Kecenderungan dari para pekerja individual ini juga lebih memilih untuk bekerja tidak di satu tempat yang sama. Saat ini belum ada tempat yang mewadahi para pekerja individual dengan tipe ini. Kebanyakan dari mereka bekerja di kantor, rumah, ditempat klien, kafe, dan di proyek. Tidak ada tempat yang representatif untuk mewadahi pekerjaan mereka. Oleh karena itu suatu wadah bagi para pekerja di era globalisasi dan teknologi informasi ini mejadi jawaban. Tempat ini haruslah mendukung teknologi canggih (high-end) dan menggunakan teknologi nirkabel (wireless). Selain itu, tempat ini juga harus senyaman mungkin guna mengurangi stress akibat pekerjaan, dan mengantisipasi rasa bosan para penggunanya, dengan tetap memerhatikan sisi fungsionalnya. 


\section{METODE PENELITIAN}

Pengumpulan data dilakukan dengan studi literatur dengan menemukan teori tentang kantor, lifestyle, perilaku pekerja individual, era-globalisasi, teknologi informasi dan nirkabel. Selanjutnya, dilakukan Survei Lapangan pada objek studi dengan menggunakan metode pengamatan (observasi), metode wawancara, dan metode kuesioner.

Metode pengamatan dilakukan untuk mendeskripsikan aktivitas pekerja individual informasi serta ruang yang dibutuhkannya. Pengamatan akan dilakukan seobjektif mungkin. Metode wawancara dilakukan untuk memperoleh keterangan dan pendapat dari pekerja individual tersebut, pemerhati masalah perilaku dan lifestyle, pemerhati masalah globalisasi dan teknologi informasi, serta para arsitek dan desain interior, yang kemudian akan digunakan sebagai bahan analisis.Metode kuesioner dilakukan untuk memperoleh keterangan dan pendapat dari pekerja individual yang bersangkutan.

Analisis data berupa pengolahan dan keterkaitan data dan informasi, dengan menggunakan metode deskripsi, pendekatan perilaku dan lifestyle, teknologi informasi dan desain. Sedangkan kerangka berpikir secara umum dapat dijelaskan pada gambar 1 berikut.

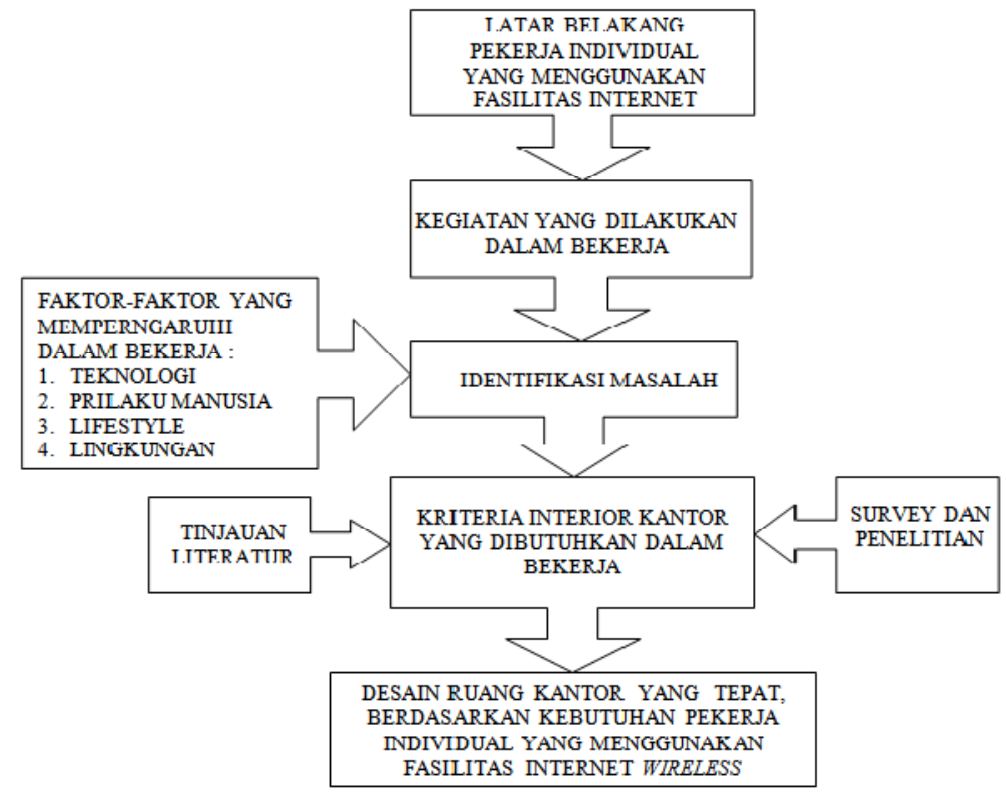

Gambar 1 skema kerangka berpikir umum

\section{HASIL DAN PEMBAHASAN}

Problema desain terjadi karena terdapat fenomena baru akibat dari pengaruh globalisasi dan perkembangan teknologi. Pertama, gaya hidup para pekerja individual yang terhubung dengan Internet menyebabkan perubahan dari konsep kantor lama yang statis menjadi lebih dinamis, karena pekerjaan lebih fleksibel. Kedua, adanya persaingan bisnis yang ketat sehingga menuntut mereka untuk bekerja dengan memaksimalkan waktu, sehingga dapat berakibat stres. Ketiga, dirasakan belum adanya wadah bagi para pekerja individu di era informasi ini, yang menampung syarat-syarat baru sebagai tempat untuk bekerja. 
Indonesia adalah salah satu negara yang mengalami era globalisasi. Djafar Hassegaff dalam buku "Indonesia dalam Era Globalisasi", mengatakan bahwa globalisasi diakibatkan oleh perkembangan komunikasi yang amat pesat yang mendorong perkembangan C\&C (computer communication). Keadaan ini mendorong pertumbuhan secara pesat bisnis data, khususnya dataseketika (real time data). Perkembangan arus lintas data membuka peluang pertumbuhan perdagangan dan bisnis yang amat pesat. Dalam dunia bisnis tumbuh perusahaan-perusahaan tanpa batas negara. Globalisasi dalam bidang informasi dan bisnis menyebabkan dunia menjadi satu dusun-dunia yang besar (global village) dengan gaya hidup dan selera global. Perkembangan teknologi yang dahsyat ini tidak dapat lagi dibendung.

Seiring dengan era globalisasi mengakibatkan tingginya persaingan dalam dunia pekerjaan. Karena seluruh orang berlomba dalam mempertahankan dan memajukan pekerjaannya, maka perilaku manusia pun berubah. Gaya hidup pekerja individual yang baru disebut E-lifestyle pada era globalisasi ini yang dalam bekerja menggunakan teknologi Internet sebagai super product-nya. Pekerja individual dengan gaya hidup E-Lifestyle dikenal sebagai E-people. Ciri E-People adalah menggunakan TIK yang up to date, cara bekerja dengan mobilitas tinggi, waktu yang fleksibel, mengutamakam citra individual, mudah terserang stress, berkurangnya waktu untuk keluarga, dan tinggal di lingkungan perkotaan.

Pekerja individual ini amat terikat dengan teknologi informasi. Karena dalam era globalisasi, teknologi informasi amat penting dalam meluaskan hubungan antargeografis, memberikan peluang lebih banyak klien dari berbagai negara. Kendala-kendala yang timbul adalah mereka tidak memiliki wadah untuk melakukan bisnisnya. Akibatnya, mereka cenderung melakukan bisnisnya di kafe atau restoran yang memiliki fasilitas wireless information technology, seperti pada gambar 2 berikut.
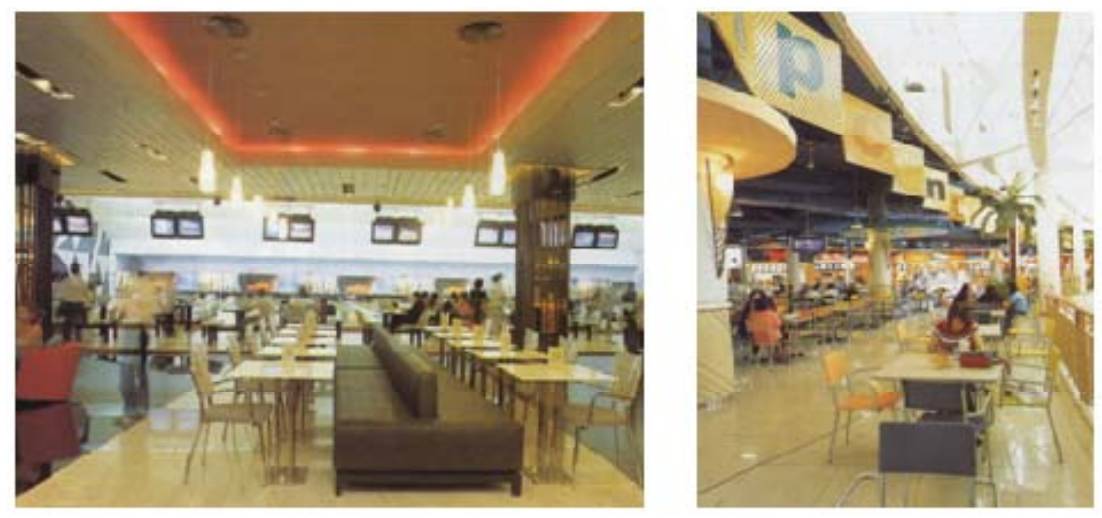

Gambar 2 restoran yang menyediakan fasilitas hotspot berlokasi di Plaza EX, Bundaran HI, Jakarta Pusat

Penggunaan teknologi informasi juga tidak lepas dari sebuah citra pekerja individual, yaitu dengan menggunakan teknologi yang up to date. Karena teknologi ini cukup mahal dan sasarannya adalah kelompok menengah keatas, maka untuk menampilkan prestise yang tinggi para pekerja individual menggunakan teknologi ini untuk menarik perhatian para klien. Penggunaan teknologi nirkabel bertujuan untuk menunjang gaya hidup pekerja individual yang memiliki mobilitas tinggi, komunikasi nirkabel lebih fleksibel dalam konektivitas ke jaringan, dan teknologi nirkabel dapat menjangkau daerah yang lebih luas dari pada yang menggunakan kabel. Dengan adanya teknologi nirkabel ini, maka membuat cara bekerja cenderung mobil atau dapat berpindah-pindah tempat guna menghemat waktu dan jarak, akibatnya sebagian besar kegiatan cenderung diluar kantor mereka demi menarik klien sebanyak mungkin dan mendekatkan jarak bertemu baik dari sisi klien maupun sisi 
pekerja individual. Mereka dapat bekerja asalkan terdapat koneksi ke Internet dari laptop mereka. Terlebih lagi pekerja yang membutuhkan inspirasi, terkadang inspirasi itu muncul tanpa mengenal waktu dan tempat.

Perilaku para pekerja individual di era globalisasi, terutama para desainer, author, dan yang lainnya tidak mengenal waktu kantor (office hours) melainkan lebih fleksibel dalam mengatur waktu kerjanya. Bisa saja bekerja pada malam hari dan istirahat pada siang hari, tetapi pada hari lainnya kerja siang hari dan istirahat malam hari. Karena sebagaian besar pekerjaan ini membutuhkan kreativitas yang tinggi, maka mereka membutuhkan suasana kerja yang tidak membosankan. Oleh karena itu tempat bekerja yang fleksibel sangat baik bagi kalangan ini.

Untuk menarik perhatian klien dan mempertahankannya, maka citra pekerja individual menjadi hal yang utama. Oleh karena itu, prestise dalam diri pekerja individual menjadi amat penting. Alfathri Aldin dalam tulisannya yang berjudul Desain, Teknologi, Gaya Hidup: Perangkat eletronik Sebagai Simbol Status Sosial, mengemukakan bahwa pada kelompok pekerja individual ini menggunakan produk perangkat elektronik dapat berubah menjadi memiliki makna simbol status sosial seperti bagaimana para eksekutif trendi menyatakan dirinya dengan memakai handphone model terbaru, jam tangan rolex, senantiasa membawa notebook. Demi mendapatkan klien, budaya bekerja menjadi tidak mengenal waktu lagi, waktu untuk menenangkan pikiran berkurang, akibatnya pekerja individual mudah terserang stres. Hal ini juga berdampak pada orang lain, terutama keluarga. Karena berubahnya lifestyle pekerja individual, maka waktu untuk keluarga semakin berkurang

Lingkungan tempat pekerja individual ini terjadi di kota-kota besar, dimana persaingan amat ketat, banyaknya pengangguran menuntut orang untuk berlomba dalam mempertahankan pekerjaannya. Kota-kota besar terutama di kota metropolitan memiliki lalu lintas yang padat yang berakibat tingginya kemacetan lalu lintas. Hal ini menyebabkan teknologi nirkabel sangat dibutuhkan sehingga mengoptimalkan waktu untuk bekerja. Dengan adanya kenyataan ini, upaya pekerja individual untuk dapat bekerja secara mobil, bertemu klien dan relaks ingin dicapai secara bersamaan. Namun pada kenyataannya, belum terdapat suatu wadah untuk menampung aktivitas ini.

Beberapa istilah yang perlu diketahui dari teknologi nirkabel ini antara lain:

\section{Wi-fi}

Wi-fi singkatan dari wireless fidelity adalah teknologi yang memungkinkan bagi pengguna komputer dan peripheral sejenis yang mendukung teknologi tersebut (PDA, telepon genggam) untuk berkomunikasi dalam jaringan LAN atau mengakses Internet dengan jaringan broadband yang tentunya tanpa kabel. Dengan menggunakan sebuah Wi-fi acces point atau router, maka akan dapat mengatur sebuah jaringan LAN atau Internet nirkabel dalam cakupan 300 square feet (300 kaki persegi) atau $\pm 100 \mathrm{~m}^{2}$. Teknologi Wi-fi terbaru dengan yang menggunakan standar dengan istilah 802.11b memiliki kecepatan transfer data dengan besaran 11 megabyte/second (Mbps). Sedangkan Wi-fi dengan standar 802.11a memiliki kecepatan transfer data sebesar 54 Mbps.

\section{Hotspot}

Dalam teknologi Wi-fi dikenal dengan adanya istilah hotspot, yang diartikan sebagai tempattempat dimana seseorang dapat mengakses Internet dengan menggunakan teknologi Wi-fi. Hotspot adalah tempat-tempat dimana kita bisa mengakses internet via jaringan Wi-fi. Singkatnya, hotspot merupakan daerah yang masuk ke dalam cakupan sebuah wi-fi access point atau router. Gambar berikut adalah gambar skema jaringan hotspot. 


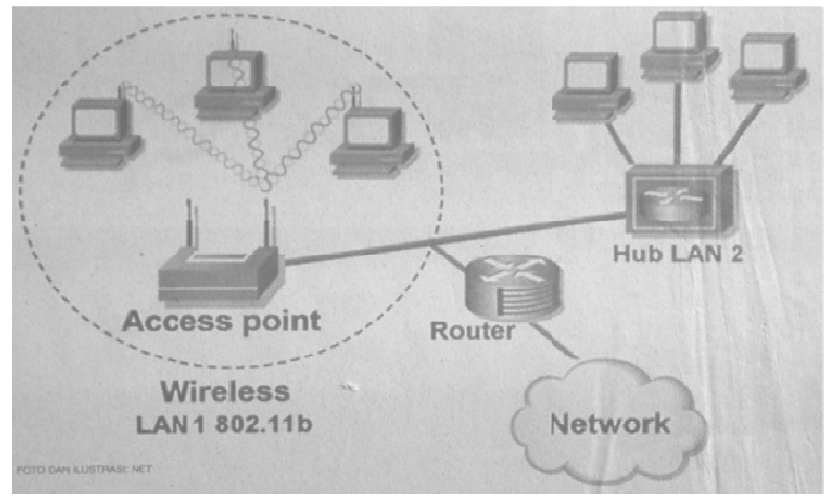

Gambar 3 Skema Jaringan Hotspot

\section{Metropolitan Area Network (MAN)}

Koneksi MAN adalah berguna untuk menghubungkan beberapa jaringan komputer (Local Area Network, $L A N$ ) dalam satu kota, misalnya LAN di kantor pusat ke LAN di lokasi lain seperti misalnya kantor cabang, gudang dan pabrik. Koneksi MAN ini memungkinkan pengolahan data secara terpusat, dan cocok untuk aplikasi seperti Enterprise Resourse Planning (ERP) dan akuntansi. Koneksi MAN dapat menggunakan radio dengan frekuensi yang berlisensi dari Ditjen Postel sehingga dapat dijamin bebas interferensinya. Koneksi ini berbasis Transmission Control Protocol/Internet Protocol (TCP/IP). Koneksi MAN memungkinkan pelanggan untuk memasang Voice over Internet Protocol (VoIP) gateway yang disambungkan ke PABX, sehingga percakapan telepon antarlokasi tidak menghabiskan pulsa telepon. Koneksi antar-LAN ini aman (secure) sehingga tidak dapat disadap oleh pihak lain. Perhatikan gambar 4 berikut mengenai skema MAN.

Layanan wireless MAN dapat lebih cost effective dibandingkan dengan lease line dari operator telekomunikasi. Keberadaan sistem wireless akan memengaruhi standarisasi kebutuhan ruang; tatanan furnitur menjadi lebih fleksibel; kantor memiliki kesan prestise yang tinggi; serta bekerja menjadi lebih efektif dan efisien. Untuk gambaran tentang jaringan Internet, lihat gambar 5.

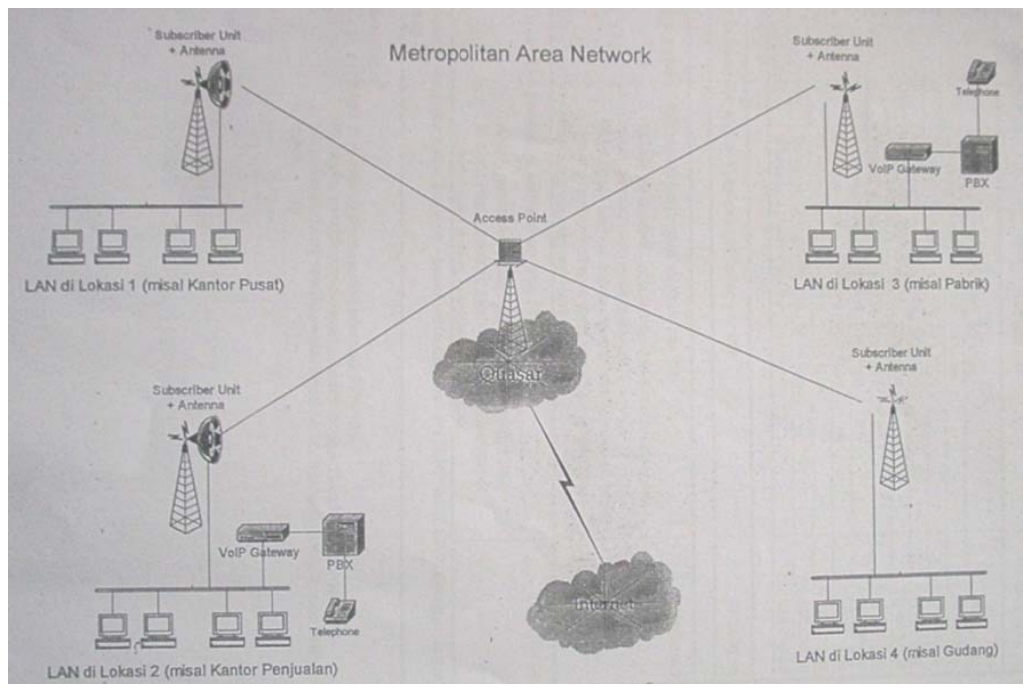

Gambar 4 skema Metropolitan Area Network 


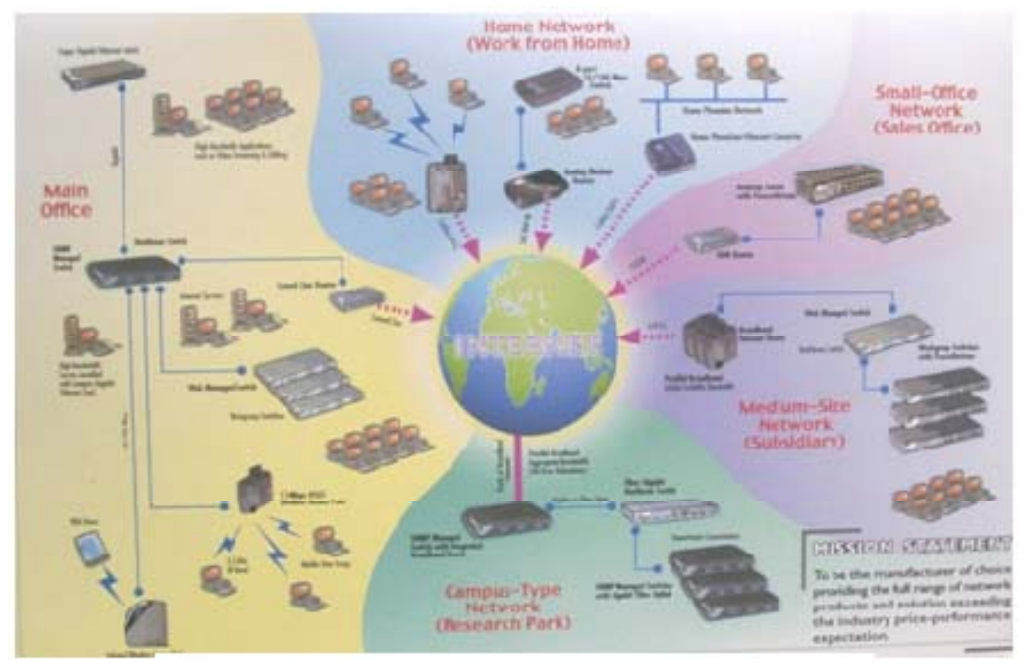

Gambar 5 Bagan Jaringan Internet

\section{Konsep Dasar Kantor Nirkabel}

Fungsi bangunan: kantor sewa jangka pendek dengan teknologi nirkabel, teknologi terkini dan koneksi internet yang cepat. Waktu operasional bangunan 24 jam. Fasilitas ini terletak pada daerah bisnis dan pada daerah yang mudah dijangkau oleh para pekerja individual tersebut. Agar dapat bekerja dengan nyaman dan terhindar dari stres maka suasana kantor bersifat santai dan memiliki fasilitas cafe. Kantor memiliki fasilitas khusus untuk para bekerja, seperti ruang meeting kecil, ruang presentasi audio-video, business centre. Selain itu, kantor memiliki pengelolaan dan manajemen terpusat dan terpadu sehingga dapat memenuhi standar penunjang dalam bekerja. Walaupun hanya kantor jangka pendek, seperti : Fasilitas fotocopy, office boy, sekretaris umum, front office dan lainnya, tidak didapatkan apabila bekerja di cafe atau di rumah.

\section{Sasaran Pengguna}

Sasaran pengguna adalah semua kalangan pekerja individual yang merupakan e-people yang bekerja berbasis Internet, dan bekerja secara individual atau dalam team kecil, antara lain seperti: arsitek, desainer interior, desainer grafik, web consultant, pengarang buku (author).

\section{Daftar Ruang}

Beberapa ruang yang ada pada kantor nirkabel, yaitu: lobby; digunakan untuk mendaftar dan kegiatan administrasi. Ruang kerja; pada pembagiannya ruang ini dibagi tiga bagian berdasarkan tingkat derajat keterbukaannya, yaitu: ruang publik, adalah ruangan untuk para e-people yang ingin bekerja dengan kondisi ruang yang terbuka dan berkesan santai. Oleh karena itu, ruangan yang disediakan memiliki derajat keterbukaan yang tinggi serta lebih mengutamakan penggunaan unsur alam pada elemen ruang sebagai sumber ketenangan. Ruang semi publik, adalah area kerja yang semi tertutup yaitu hanya dibatasi dengan sekat tanpa pintu untuk batas privasi. Ruang privat, adalah area kerja yang sifatnya tertutup dan lebih privat dari ruangan yang lain. Didalam ruangan ini hanya dapat digunakan oleh satu pengguna dan ruangan ini dapat sekaligus digunakan untuk rapat dan menjamu klien. Ruang rapat (meeting room); digunakan untuk rapat, sifat ruang sangat privat, dengan menggunakan sistem peredam suara pada dindingnya. Ruang Fotokopi dan penunjang lainnya; tempat pelanggan melakukan fotokopi, scan, print, fax. Ruang server; tempat pusat komputer dan konektivitas melalui Internet dan nirkabel. Ruangan server ini harus dapat berjalan selama 24 jam sehari dan 7 hari seminggu. Oleh karena itu diperlukan perangkat keras yang berkualitas, sistem 
perangkat lunak yang terbaru dan efisien, serta sistem back-up (cadangan) untuk data dan daya listrik. Café; berfungsi sebagai penunjang yang diperlukan di bangunan ini, karena sebagai penyedia makanan dan minuman, dan sebagai tempat bertemu informal, atau sebagai tempat sharing sesama pengguna.

\section{Persyaratan Ruang}

Berikut dibahas mengenai persyaratan ruang yang dibutuhkan dalam mendesain kantor, yaitu faktor kenyamanan ruang, standarisasi ruang kerja privat (private workstation), ruang kerja publik (public workstation), dan standarisasi ruang rapat (meeting room).

\section{Kenyamanan Ruang Kerja}

Untuk menciptakan kenyamanan ruang, ruang kerja dibagi menjadi beberapa area, dan dibuat tabel kenyamanan ruang dengan beberapa faktor seperti penerangan alami, penerangan buatan, ketenangan, pemandangan (view), ventilasi, dan akustik. Perhatikan tabel berikut.

Tabel 1 Tabel kenyamanan ruang kerja

\begin{tabular}{|c|c|c|c|c|c|c|c|c|c|c|}
\hline & 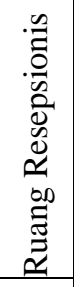 & 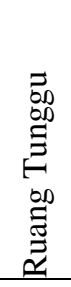 & 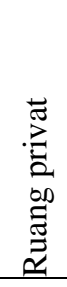 & 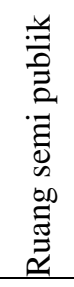 & 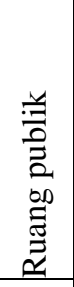 & 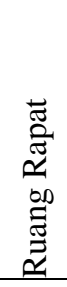 & 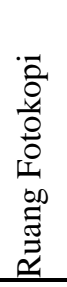 & 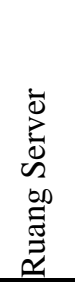 & $\frac{8}{3}$ & 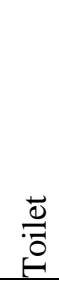 \\
\hline Penerangan alami & $\mathrm{O}$ & $\mathrm{O}$ & $\mathrm{O}$ & $\mathrm{O}$ & $\mathrm{O}$ & $\mathrm{O}$ & $\mathrm{O}$ & $\mathrm{O}$ & $\mathrm{O}$ & $\mathrm{O}$ \\
\hline Penerangan buatan & $\mathrm{O}$ & $\mathrm{O}$ & $\mathrm{O}$ & $\mathrm{O}$ & $\mathrm{O}$ & $\mathrm{O}$ & $\mathrm{O}$ & $\mathrm{O}$ & $\mathrm{O}$ & $\mathrm{O}$ \\
\hline Ketenangan & & & $\mathrm{O}$ & $\mathrm{O}$ & & $\mathrm{O}$ & & & & \\
\hline Pemandangan / View & $\mathrm{O}$ & $\mathrm{O}$ & $\mathrm{O}$ & & & & & & $\mathrm{O}$ & \\
\hline Ventilasi & $\mathrm{O}$ & $\mathrm{O}$ & $\mathrm{O}$ & $\mathrm{O}$ & $\mathrm{O}$ & $\mathrm{O}$ & $\mathrm{O}$ & $\mathrm{O}$ & $\mathrm{O}$ & $\mathrm{O}$ \\
\hline Akustik & & & $\mathrm{O}$ & & & $\mathrm{O}$ & & & & \\
\hline
\end{tabular}

\section{Standarisasi Ruang Kerja}

Ruang kerja harus memenuhi standar ukuran yang meliputi zona kerja yang cukup untuk menampung pemakai dan kebutuhan peralatan kantor. Syarat-syarat terbentuknya standarisasi ruang kerja tersebut adalah: data Antropometrik yang menghasilkan dimensi tempat duduk dan dimensi meja, hubungan antara pemakai pada posisi duduk dengan meja tulis, zona kebutuhan kerja, jarak bersih penempatan tempat duduk disekitar meja, jarak bersih penempatan peralatan, dimensi dan jarak furnitur lainnya, dan jarak sirkulasi. Berdasarkan sifat dasar dari bisnis dan kebiasaan kerja tertentu dari eksekutif tersebut, ruang kerja dibagi menjadi ruang kerja privat dan ruang kerja publik. 


\section{Standarisasi Ruang Kerja Privat (Private Workstation)}

Berikut adalah gambar standarisasi ruang kerja privat yang dihasilkan:

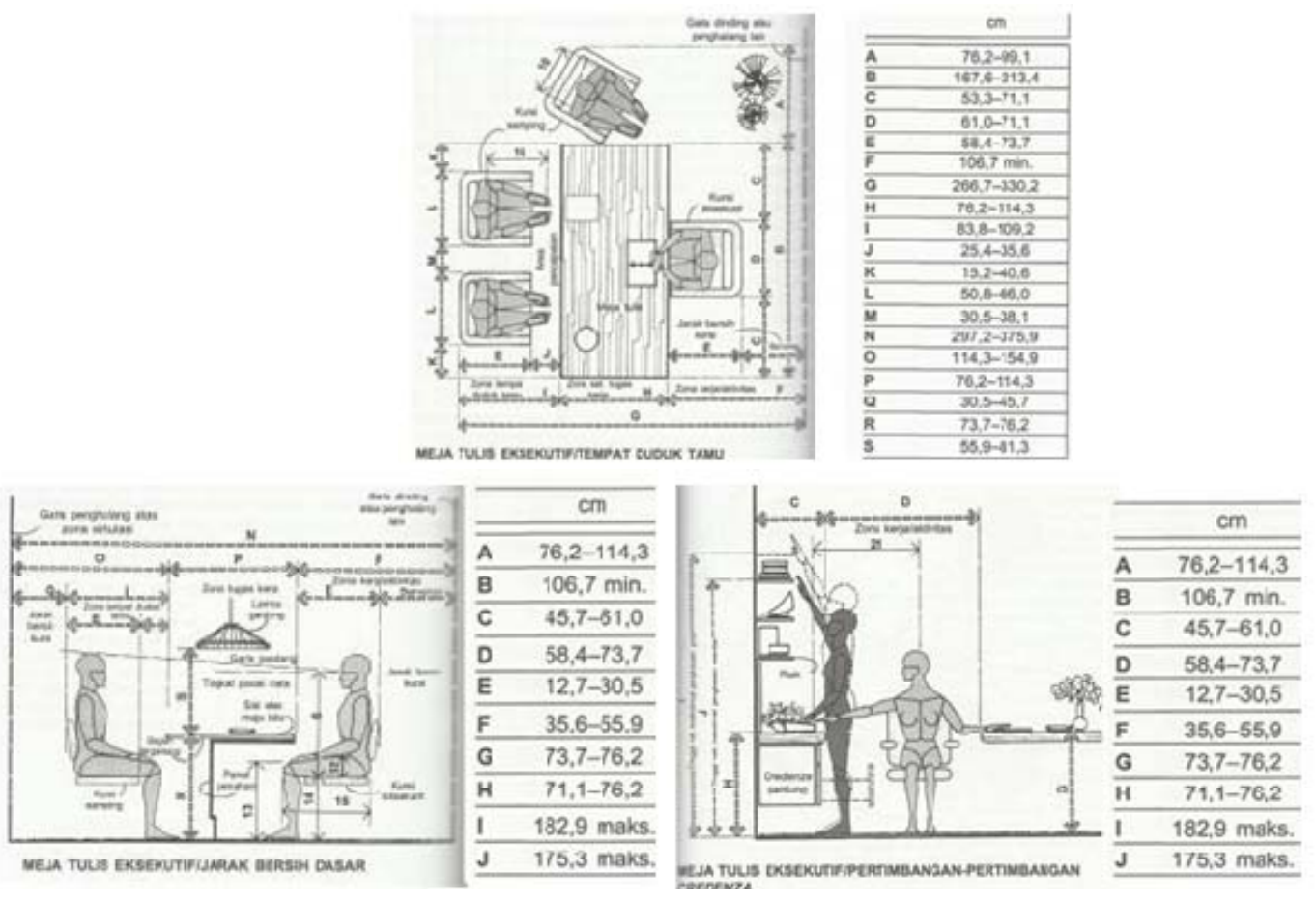

Gambar 6 standarisasi ukuran dan denah ruang kerja privat

\section{Standarisasi Ruang Kerja Publik (Public Workstation)}

Berikut adalah gambar standarisasi ruang kerja publik yang dihasilkan:
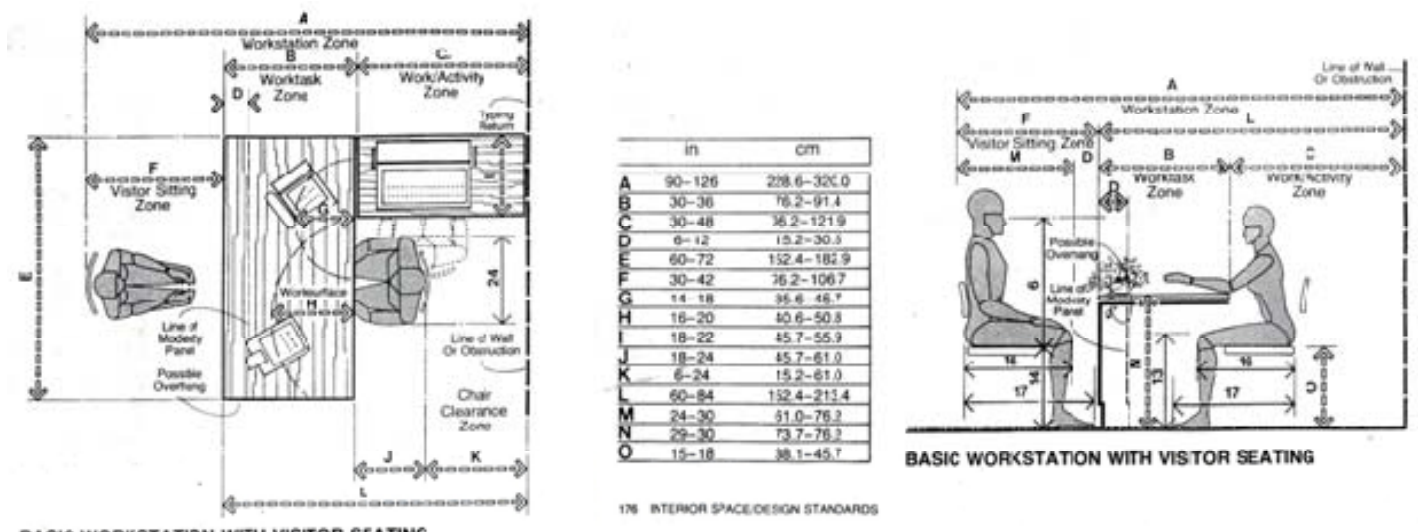

BASIC WORKSTATON WITH VISTOR SEATING

BASIC WORKSTATION WITH VISITOR SEATING

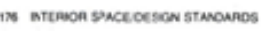

Gambar 7 standarisasi ukuran dan denah ruang kerja dengan tamu (pengunjung) 

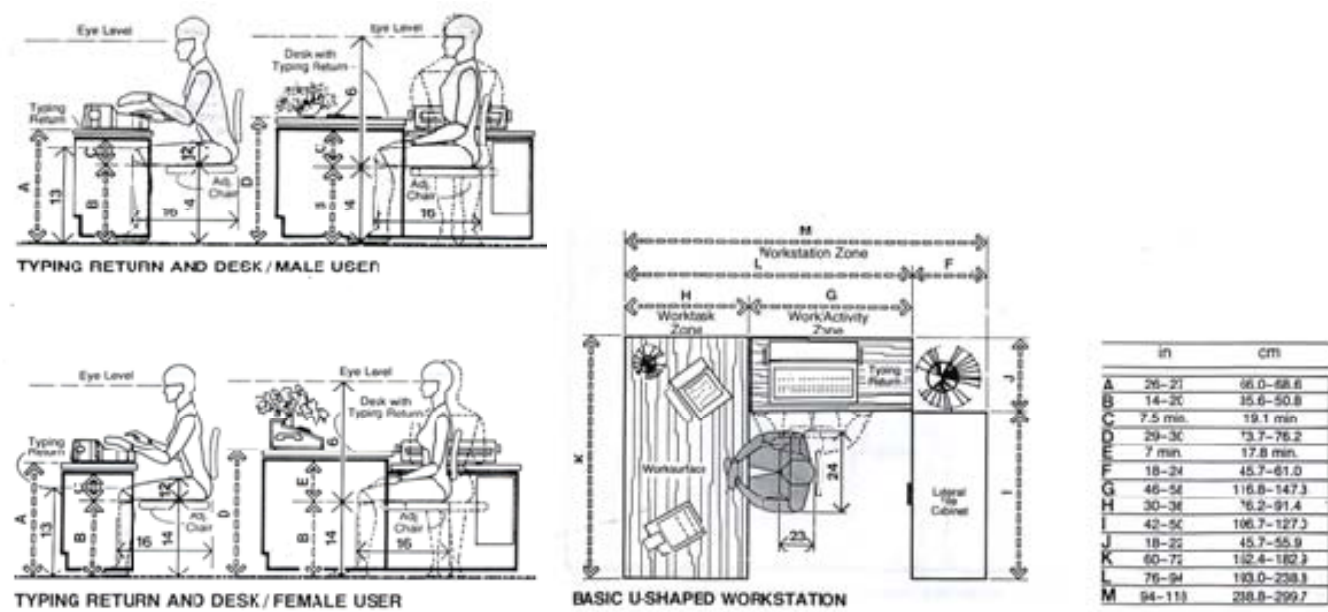

Gambar 8 standarisasi ukuran dan denah ruang kerja publik

\section{Standarisasi Ruang Rapat (Meeting Room)}

Ruang rapat terdiri dari tiga macam, yaitu: ruang rapat kecil (small conference room), ruang rapat sedang (medium conference room), dan ruang rapat besar (large conference room). Perhatikan gambar 9 berikut ini untuk denah ruang rapat.

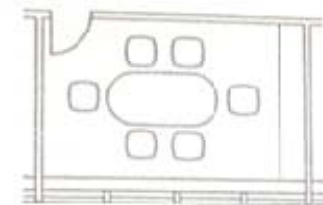

SMALL CONFERENCE ROOM

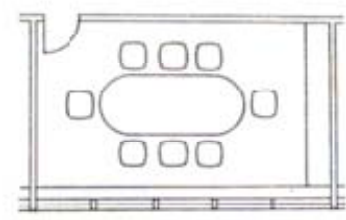

MEDUM CONFEAENCE ROOM

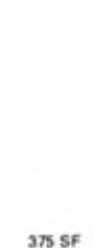

37s SF

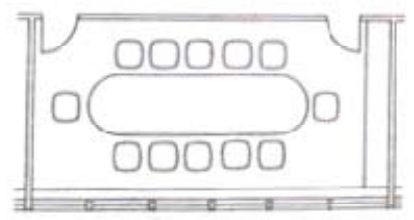

LAPGE CONFERENCE ROOU

Gambar 9 Gambar denah ruang rapat

\section{Flow of Actifity}

Berikut ini adalah skema aktivitas pengguna ruang, yaitu karyawan dan staf, yang menghasilkan kebutuhan ruang.

\section{Aktifitas Karyawan}

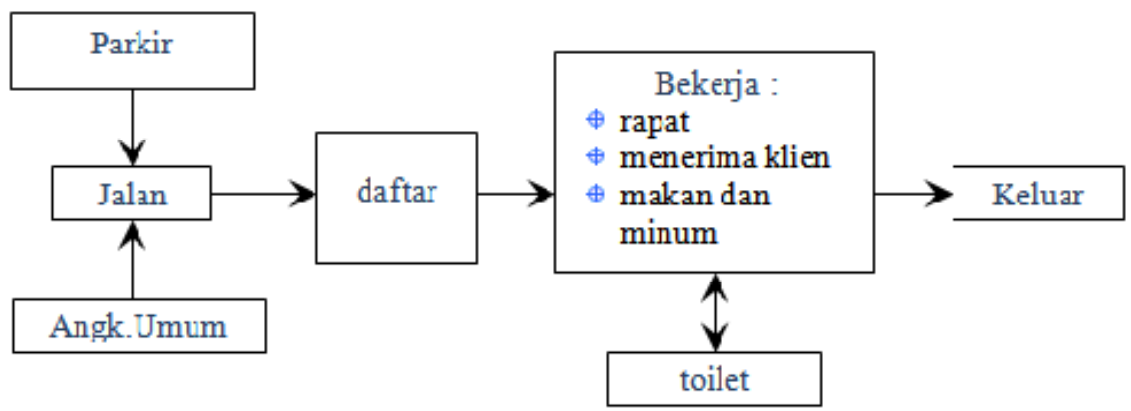

Gambar 10 Skema aktivitas karyawan 


\section{Kebutuhan Ruang Karyawan}

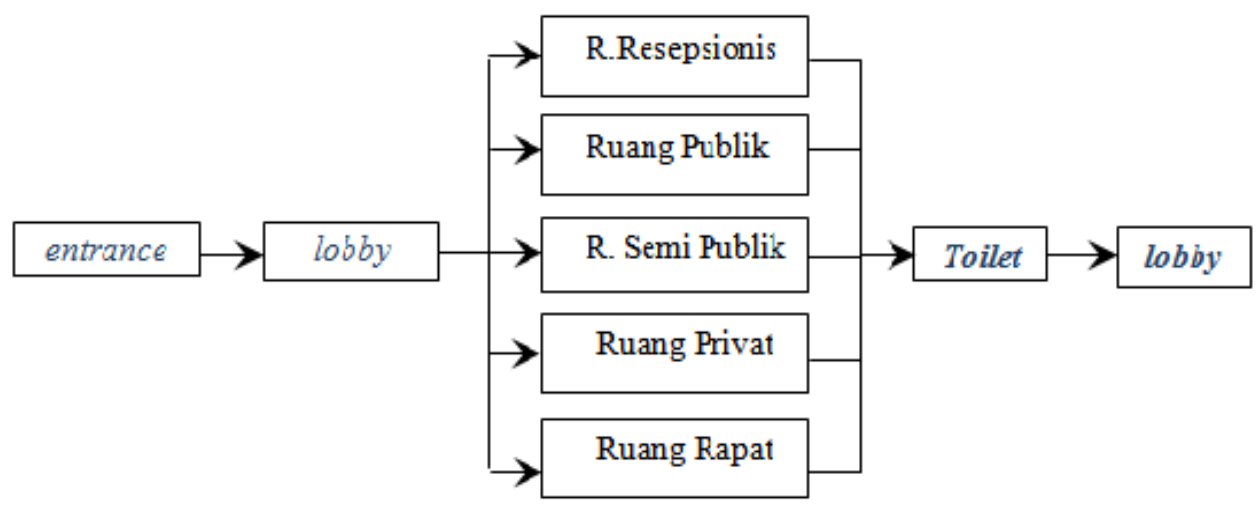

Gambar 11 Skema kebutuhan ruang karyawan

\section{Aktivitas Staf}

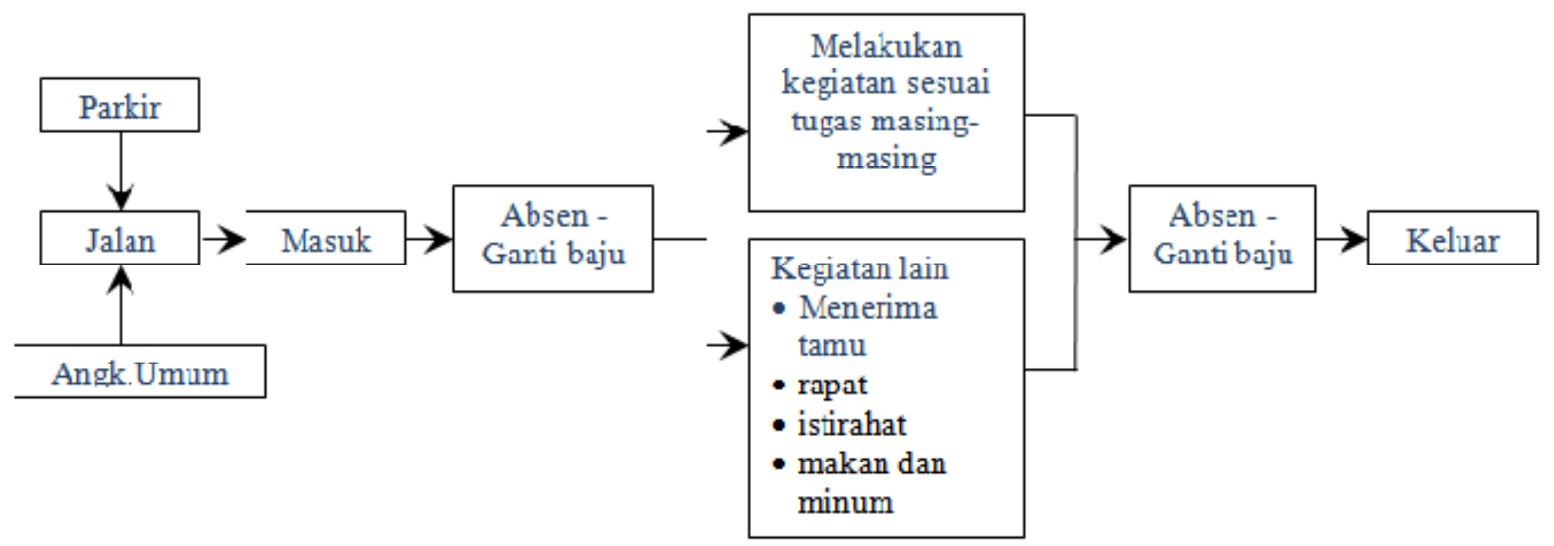

Gambar 12 Skema aktivitas staf

\section{Kebutuhan Ruang Staf}

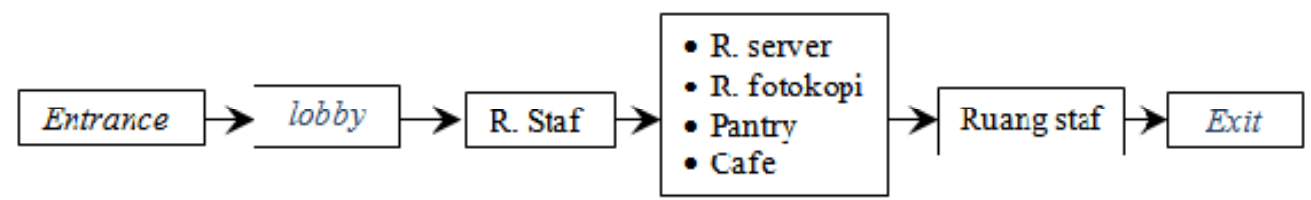

Gambar 13 Skema kebutuhan ruang staf 


\section{SIMPULAN}

Kehadiran teknologi Internet dan nirkabel telah menciptakan sebuah budaya baru pada masyarakat Indonesia. Para pekerja lepas yang bekerja secara individual atau secara tim kecil memiliki gaya bekerja yang berbeda dan tidak konvensional. Cara bekerja yang dimaksud adalah penggunaan media Internet dan konektivitas nirkabel dalam bekerja sehingga tidak terikat oleh tempat bekerja dan memiliki mobilitas tinggi. Saat ini para pekerja tersebut banyak melakukan aktivitas bekerja di rumah atau kafe. Contoh dari para pekerja ini adalah arsitek, desainer interior, web consultant, pengarang buku (author). Dengan adanya budaya bekerja yang baru tersebut, maka timbullah suatu gagasan tentang sebuah kantor sewa jangka pendek, dengan fasilitas yang lengkap, dengan teknologi yang mutakhir yang dapat mewadahi budaya kerja yang baru tersebut. Tempat ini dapat disebut virtual office, dimana pengguna menggunakan tempat ini hanya untuk bekerja dalam waktu jangka pendek (harian atau mingguan), dengan mengutamakan efisiensi bekerja. Tempat bekerja ini harus berada di lokasi yang strategis dan mudah dijangkau, baik dengan kendaraan pribadi atau transportasi publik. Kantor ini berada di beberapa titik di seluruh kota, dan membentuk sebuah jaringan. Hal ini akan mengantisipasi dunia bisnis yang semakin cepat dan efisien. Peran desainer interior akan menjadi sangat penting karena kantor ini tidak hanya fungsional, tetapi haruslah menciptakan suasana nyaman dalam bekerja. Bahkan, menjadi tempat yang memberikan inspirasi pada pengguna. Selain itu, setiap ruangan harus dapat dimanfaatkan dengan efisien dan efektif, tanpa mengurangi faktor kenyamanan dan keindahan. Adanya kebutuhan ini merupakan sebuah tantangan dan peluang bagi para desainer interior dalam menjawab kebutuhan manusia yang selalu berubah dan meningkat sesuai dengan perkembangan jaman.

\section{DAFTAR PUSTAKA}

Ibrahim, I. S. (ed). (1997). Lifestyle Ecstasy, Kebudayaan Pop dalam Masyarakat Komoditas Indonesia. Bandung: Mizan.

Laurens, J. M. (2004). Arsitektur dan perilaku Manusia. Jakarta: Grasindo. Metodologi dan Aplikasi. Jakarta: Direktorat Jenderal Pendidikan Tinggi Departemen P\&K.

Panero, Julius. (1979). Human Dimension \& Interior Space. New York: Whitney Library of Design.

Rayfield, J. K. (1994). The Office An Introduction Interior for Facility and Design Professionals Guide. New York: John Wiley and Sons.

Sarwono, S. W. (1995). Psikologi Lingkungan. Jakarta: Grasindo.

Setiawan, B., \& Haryadi. (1995). Arsitektur Lingkungan dan Perilaku: Suatu Pengantar ke Teori,

Silalahi, N. (2002). Layanan Informasi dan Telekomunikasi Mobil Nirkabel. Jakarta: Elex Media Komputindo.

Widyahartono, B. (ed). (1990). Indonesia Dalam Era Globalisasi: Dimensi Baru Asia Pasifik Abad 21. Jakarta: Bank Summa. 